\title{
Ensino da compreensão leitora na prática pedagógica de professores do ensino fundamental
}

\section{Teaching of reading understanding in the pedagogical practice of fundamental teaching teachers}

https://doi.org/10.34112/2317-0972a2019v37n76p89-108

\author{
Elaine Doroteia Hellwig Braz ${ }^{1}$ \\ Sandra Regina Kirchner Guimarães ${ }^{2}$
}

RESUMO: A aprendizagem da leitura é um processo complexo que requer a instalação de diversas habilidades linguístico-cognitivas, que depende de ensino explícito. Este estudo analisa os dados coletados na observação de práticas pedagógicas para o ensino da compreensão da leitura adotadas por professoras de $3 .^{\circ} \mathrm{e} 4 .^{\circ}$ ano do ensino fundamental, em uma escola municipal de Curitiba-PR. Como instrumento para coleta/registro das informações foi utilizada uma pauta de observação contendo 33 itens, organizada para registrar as estratégias didáticas utilizadas pelas professoras antes, durante e depois da leitura de texto. Verificou-se que a maior parte das estratégias de ensino são realizadas após a leitura e que, normalmente, essas atividades são voltadas para a compreensão literal das informações veiculadas pelos textos. Conclui-se pela necessidade de aprimoramento do ensino da compreensão leitora, o qual deve focalizar a capacidade de o leitor reorganizar as informações do texto e alcançar uma compreensão inferencial e crítica. Palavras-chave: Compreensão da leitura; estratégias de leitura; ensino da compreensão leitora.

ABSTRACT: The learning of reading is a complex process that requires the establishment of several linguistic-cognitive skills, which depends on explicit teaching. This study analyzes

1. Prefeitura Municipal de Curitiba, Curitiba, PR, Brasil.

2. Universidade Federal do Paraná, Curitiba, PR, Brasil. 
Ensino da compreensão leitora na prática pedagógica de professores...

the data collected in the observation of pedagogical practices for the teaching of reading comprehension adopted by 3 rd and 4 th grade elementary school teachers in a city hall school in Curitiba-PR. As an instrument for collecting / recording the information, an observation list containing 33 items was used, organized to record the didactic strategies used by the teachers before, during and after reading the text. It was found that most teaching strategies are carried out after reading and that, normally, these activities are focused on the literal understanding of the information conveyed by the texts. It concludes the necessity of improvement the teaching of reading comprehension, which should focus on the reader's ability to reorganize text information and achieve inferential and critical understanding. KEYWORDS: Reading comprehension; reading strategies; teaching reading comprehension.

\section{A Leitura}

Conhecer a linguagem escrita oficial do país é fundamental para qualquer cidadão (MALUF, 2005). O ensino da leitura e da escrita em um sistema alfabético exige que o professor tenha conhecimentos tanto sobre o funcionamento do sistema de escrita, quanto sobre como os estudantes o aprendem. Na leitura, em especial, reconhecer os elementos que estão presentes no texto e analisá-los ajudará na construção de sentido para que a compreensão aconteça. Para explicar a compreensão textual, Morais (2013) considera que existem duas ideias-base essenciais a serem levadas em conta. A primeira é que a identificação das palavras é condição sine qua non para a compreensão do texto e a segunda é que essa identificação seja automática.

Dito de outro modo, a possibilidade de um leitor entender um texto está atrelada à sua capacidade de identificar as palavras escritas, ressaltando-se que é muito importante, para uma compreensão bem-sucedida, que essa identificação seja feita automaticamente. Corroborando esse pressuposto, Alégria, Leybaert e Mousty (1997) argumentam que, quando não há automatismo na leitura, o leitor dispensa tanto esforço cognitivo para decifrar cada uma das palavras que constituem o texto, ou seja, para a decodificação, que acaba sobrando muito pouco ou quase nada para se investir na compreensão. Com isso, depreende-se, então, que as dificuldades de compreensão podem ser fruto da falta de habilidade de identificação de vocábulos nos textos.

A segunda ideia-base, exposta como identificação automática das palavras, refere-se ao fato de que a compreensão envolve conhecimentos da morfologia e da sintaxe, sendo que, nem sempre, o leitor reflete sobre ou controla intencionalmente esses conhecimentos. 
Os estudos e pesquisas que focalizam o trabalho pedagógico com leitura são abundantes, mas muito dos conhecimentos por eles veiculados não têm sido incorporados na prática pedagógica dos professores e, por isso, pouco contribuem para a melhoria da aprendizagem em leitura dos estudantes. Destaca-se, especialmente, a necessidade de os professores se apropriarem deste conhecimento de forma sistemática e refletida. Conforme Jouve (2002) a interação produtiva entre o leitor e o autor é que torna a leitura eficiente. A leitura nos anos iniciais é fundamental para o sucesso do estudante, mas o simples contato com ela não é suficiente para que a aprendizagem se efetive. Como destaca Rojo (2004) o foco da leitura de um texto não está apenas na decodificação, quando o leitor transpõe o código escrito para o oral, mas na compreensão do que está sendo lido. O leitor deve assumir um papel ativo, criando sentido ao texto a partir dos conhecimentos que tem, mas isso não significa que se pode realizar qualquer interpretação. Conforme Giasson (2003) os autores ao produzirem seus textos normalmente deixam de lado informações supostamente conhecidas pelos leitores, pois se tiverem que colocar todas as informações, os textos ficariam enormes e muitos leitores acabariam por não ler o que foi escrito. Devido a isso, para que haja a compreensão, há necessidade de interação entre o texto, o conhecimento que o leitor possui e o contexto onde acontece essa relação.

O conhecimento prévio que o leitor possui é essencial na compreensão, pois a partir do estabelecimento das relações entre o que está posto no texto e o conhecimento que o leitor possui gera-se a compreensão, ou seja, os conhecimentos prévios do leitor influenciam na compreensão do que está sendo lido. Com isso, como diz Giasson (2003) a maior possibilidade de sucesso na compreensão da leitura se dará a partir dos conhecimentos que os estudantes possuem, quanto mais conhecimento melhores resultados na compreensão.

A abordagem a um texto acontece em vários níveis, a integração destes níveis fornece os recursos necessários para que a compreensão se efetive. Giasson (2003) classifica esses níveis como microprocessos, processos de integração, macroprocessos, processos de elaboração e processos metacognitivos. Em cada um desses processos respectivamente são trabalhados:

- na frase, o entendimento das palavras que a compõe;

- na integração entre as frases, os elementos de coesão, importantes para produção dos sentidos do texto; 
Ensino da compreensão leitora na prática pedagógica de professores...

- na coerência, a compreensão global, pois está baseada no sentido que se quer transmitir;

- na inferência, a realização de relações entre o que está explícito e o que está implícito no texto;

- nos processos metacognitivos, a possibilidade de o leitor ter consciência do que está lendo e das relações que está executando.

Atrelado à compreensão da leitura está o texto, tanto oral quanto escrito. O texto influencia na compreensão. Conforme a estrutura, ou seja, dependendo de como estão organizadas as informações, elas podem ajudar ou dificultar a compreensão. Além da organização das informações, o conteúdo e a linguagem utilizada também influenciam na compreensão. Outro ponto importante a respeito dos textos é a intenção de comunicação. Como aponta Costa (2009, p. 16) os gêneros textuais são "formas relativamente estáveis de enunciado", pois ao levar em consideração o público a que se destina o texto e a intenção, tanto a linguagem quanto a estrutura podem ser modificadas para atingir o objetivo comunicacional.

Porém os autores têm a liberdade de misturar os gêneros textuais (intergenericidade), ou seja, escrever um gênero com a estrutura de outro para transmitir determinada sensação, modificando formas de pensar e causando até estranheza ao leitor. Além da intergenericidade, Marcuschi (2008) traz outros tipos de relações presentes nos textos como a intertextualidade (presença de um texto em outro), a paratextualidade (o entorno do texto), a metatextualidade (comentários de um texto), a arquitextualidade (o texto em relação à classe que pertence) e a hipertextualidade (paródia, pastiche). Essas relações proporcionam ao leitor diversas possibilidades de interpretação, faz com que os textos sejam interessantes, mas dificultem a compreensão de leitores não habilidosos. Nas salas de aula do ensino fundamental, muitos dos textos trabalhados apresentam as relações de intergenericidade (convite e receitas em forma de poema, etc.) e de intertextualidade as quais os estudantes conseguem compreender com a ajuda do professor.

Além do texto, da mistura de estruturas e de todas as relações descritas o contexto também influencia na compreensão, ou seja, durante uma leitura, a motivação, o interesse e a intenção do leitor influencia diretamente na compreensão. Giasson (1993, p. 40) diz que "a maneira como o leitor aborda o texto influenciará o que ele vier a compreender e a reter dele". Por último, não se pode deixar de mencionar que existe também a influência do ambiente físico. 
O ENSINO DA COMPREENSÃO

Muitas vezes ao ler, o estudante se depara com muitas dúvidas, há necessidade de que o professor aproveite esses momentos para resgatar os conhecimentos prévios dos estudantes para fazê-los interagir, concordando ou discordando do que está sendo lido, ou seja, a leitura com compreensão implica em conseguir relacionar os fatos presentes no texto com o conhecimento que o leitor possui, o que possibilita a realização de inferências permitindo a compreensão do texto. A realização das inferências devem ser oportunidades para o ensino e a reflexão do que está expresso no texto. Conforme Oliveira (2003) a compreensão da leitura é um processo complexo que inclui a maneira como o leitor se envolve com o texto, esse envolvimento se dá a partir da produção de inferências e as favorece.

$\mathrm{Na}$ escola, o trabalho pedagógico de relacionar os conhecimentos que os estudantes já possuem com o que estão lendo proporciona a realização das inferências, daí a importância de que este trabalho seja feito de forma sistematizada, viabilizando o ensino da compreensão. Para que isso aconteça, é necessário então, que o professor utilize diferentes procedimentos e estratégias, com o objetivo de desenvolver capacidades/habilidades de leitura e, consequentemente, aumentar o domínio da compreensão leitora dos estudantes.

Vários estudos (GIASSON, 1993; SOLÉ, 1998; VIANNA et al, 2010) apontam que o ensino explícito e sistemático é eficiente em promover aumento na compreensão da leitura. Catalá et al. (2013) propõem quatro componentes (níveis) da compreensão da leitura, classificados como compreensão: literal, reorganizativa, inferencial e crítica. Nas atividades de compreensão literal estão as que proporcionam o reconhecimento de tudo o que está explícito no texto. As atividades de reorganização referem-se a aquelas que sintetizam o que foi lido por meio de esquemas, sínteses, resumos e outros. Já a compreensão inferencial ocorre quando há o acionamento do conhecimento prévio do leitor, que em interação com as informações explícitas no texto possibilita a compreensão do que está implícito. Catalá et al. (2013) destacam que a inferência é a verdadeira essência da compreensão leitora. Um último nível proposto pelas autoras refere-se à compreensão crítica, que abrange a formação de juízo sobre o conteúdo do texto, a partir de argumentos pertinentes.

Giasson (1993) apresentou um modelo de ensino explícito da compreensão leitora, cuja característica é propiciar situações de ensino em que a leitura seja integral e significativa para os estudantes. Para esse ensino aponta cinco etapas: 
definir as estratégias e sua utilidade; tornar o processo transparente; interagir com os estudantes e orientá-los para o domínio da estratégia; favorecer a autonomia do estudante na utilização da estratégia e assegurar a aplicação da estratégia.

Neste sentido, salienta que o professor precisa saber que os estudantes não conhecem as estratégias que podem auxiliá-los na compreensão da leitura. Por isso, nos momentos de ensino, é importante orientar os estudantes sobre que estratégia de leitura utilizar, explicando como ela poderá ajudar na compreensão do texto. Por exemplo: para tornar o processo transparente, ao ler em voz alta, quando aparece uma palavra desconhecida, o professor pode propor diversas estratégias para compreendê-la como: utilizar as pistas que o texto fornece para antecipar significados, analisar a raiz da palavra ou os seus afixos, ou mesmo, fazer uma pesquisa no dicionário. Ao escolher buscar pistas no texto o professor solicita que digam o que acham que significa a palavra, na sequência continua a leitura e à medida que avança questiona os estudantes se realmente o que disseram é confirmado ou não. Ao ensinar explicitamente a compreensão da leitura é importante saber como fazer; o que fazer; porque e quando fazer. Tendo como referência Giasson (1993) foi elaborado o quadro 1, que apresenta os processos necessários à compreensão do texto, a maneira como estes processos operam, bem como, exemplos de ações/atividades oriundas destes processos. Os processos não são hierárquicos, acontecem simultaneamente. 


\begin{tabular}{|c|c|c|}
\hline \multicolumn{3}{|c|}{ Processos nexessários à comp reensão } \\
\hline Processo & Operação & Ações/estratégias \\
\hline Microprocessos & $\begin{array}{l}\text { Permitem a compreensão de } \\
\text { informações contidas numa } \\
\text { frase. }\end{array}$ & $\begin{array}{l}\text { - Reconhecer as palavras; } \\
\text { - Ler grupos de palavras em unidades } \\
\text { significativas; } \\
\text { - Microsseleção, ov seja, selecionar os } \\
\text { elementos importantes de uma frase. }\end{array}$ \\
\hline $\begin{array}{l}\text { Processos de } \\
\text { integração }\end{array}$ & $\begin{array}{l}\text { Permitem o es tab elecimento } \\
\text { de relações entre as } \\
\text { proposições ov entre frases e } \\
\text { também inferir quais relações } \\
\text { estão implicitas. }\end{array}$ & $\begin{array}{l}\text { - Compreender os referentes e os conectores e } \\
\text { inferir as relações entre as proposições e as } \\
\text { frases e entre as frases e o texto; } \\
\text { - Reconhecer os elementos de conexão; } \\
\text { - Realizar inferências. }\end{array}$ \\
\hline Macroprocessos & $\begin{array}{l}\text { Permitem a compreensão do } \\
\text { texto como um todo. }\end{array}$ & $\begin{array}{l}\text { - Extrair a ideia principal ov informação } \\
\text { importante em um texto; } \\
\text { - Produzir resumo; } \\
\text { - Conhecer a estrutura dos textos. }\end{array}$ \\
\hline $\begin{array}{l}\text { Processos de } \\
\text { elaboração }\end{array}$ & $\begin{array}{l}\text { Permitem que o leitor } \\
\text { estabeleça relações entre o } \\
\text { texto e sevs conhecimentos } \\
\text { prévios. }\end{array}$ & $\begin{array}{l}\text { - Fazer previsões; } \\
\text { - Construir imagens mentais; } \\
\text { - Reagir emotivamente; } \\
\text { - Falar sobre o texto; } \\
\text { - Integrar a informação nova aos } \\
\text { conhecimentos anteriores. }\end{array}$ \\
\hline $\begin{array}{l}\text { Processos } \\
\text { metacognitivos }\end{array}$ & $\begin{array}{l}\text { Permitem que o leitor se } \\
\text { adapte ao texto e à situação. } \\
\text { Diz respei to à utilização de } \\
\text { estratégias de estudo, aos } \\
\text { conhecimentos que o leitor } \\
\text { possui sobre seu processo de } \\
\text { leitura. }\end{array}$ & $\begin{array}{l}\text { - Conhecer seus próprios conhecimentos } \\
\text { (conhecer as potencialidades e dificuldades } \\
\text { enquanto leitor); } \\
\text { - Av torregulação (saber quando compreende; } \\
\text { o que compreende; saber do que precisa para } \\
\text { compreender e fazer os ajustes necessários) }\end{array}$ \\
\hline
\end{tabular}

Quadro 1: Processos necessários à compreensão

Fonte: Elaborado pelas autoras com base em Giasson (1993).

Durante o processo de ensino da compreensão, primeiramente o professor realiza atividades que antecedem a leitura do texto, buscando ativar os conhecimentos prévios dos estudantes no que se refere ao conteúdo do texto (GIASSON, 1993; SOLÉ, 1998).

Em relação às atividades durante a leitura, Giasson (1993) destaca inicialmente a importância de o professor focalizar os microprocessos com as seguintes atividades: leitura repetida; leitura de um texto escrito ao mesmo tempo em que é ouvida uma gravação dele; leitura do texto em trechos (unidades significativas); solicitação de que os estudantes encontrem a ideia principal de determinadas frases; realização de reconto do texto lido. Além das atividades de microprocesso, o professor deve focalizar em atividades que possibilitam a integração, como por exemplo: o levantamento de hipóteses; 
a identificação de palavras-chave; perguntas do tipo sim-não; escolha de passagem do texto com conectores e interpretação do significado desta conexão; elaboração de enunciados que liguem duas proposições; leitura de trechos do texto e realização de perguntas que demandem inferências. No tocante às atividades de macroprocesso, uma das atividades mais expressivas para a compreensão leitora é a realização de resumo oral ou escrito sobre o conteúdo do texto lido. Além disso, é possível destacar também os processos de elaboração como atividades auxiliares à compreensão. Nesta dimensão pode-se citar as seguintes atividades: realização de previsões (a partir de indícios como o título do texto e ilustrações) sobre personagens ou sobre o que vai acontecer na sequência do texto; confirmação ou infirmação das previsões; distinção entre os fatos e opiniões, bem como, distinção entre aspectos conotativos e denotativos nos textos. Por último, destaca-se as atividades para o desenvolvimento dos processos metacognitivos, os quais são imprescindíveis para que os estudantes adquiram autonomia como leitores. Esses processos reúnem todas as atividades de monitoramento da compreensão leitora por parte dos estudantes e permitem a realização de reflexões sobre o texto: sua forma (partes constituintes e objetivo de cada uma), o conteúdo apresentado no texto, o que do conteúdo é semelhante ao que já sabia (conhecimento prévio) e o que é novo. Além disso, os processos metacognitivos envolvem a auto-regulação da compreensão, ou seja, a consciência do leitor sobre o que entendeu e o que não entendeu do texto, bem como, o planejamento do que deve fazer para aprimorar a própria compreensão.

Nesta perspectiva, o ensino explícito da compreensão da leitura deve objetivar o ensino de estratégias de leitura aos estudantes.

Em síntese, é possível afirmar que as estratégias utilizadas antes e durante a leitura auxiliam para que o leitor se situe diante do texto. Assim, embora as diferentes estratégias possam ser utilizadas em todos os momentos, uma vez que não são rígidas, as hipóteses que o leitor construiu inicialmente o auxiliam a buscar no texto informações para confirmá-las ou refutá-las. Além disso, as estratégias utilizadas durante a leitura permitem que o leitor resolva os problemas ou lacunas na compreensão que possam aparecer no decorrer do processo. Por último, as estratégias utilizadas após a leitura retomam alguns aspectos já realizados antes e durante a leitura com o objetivo de dirimir possíveis dúvidas remanescentes e confirmar a compreensão.

Inserido neste contexto teórico, o objetivo deste estudo foi investigar elementos de resposta à seguinte questão norteadora da pesquisa: Como se caracterizam as estratégias de ensino da compreensão leitora utilizadas pelos professores, antes, durante e após a leitura dos textos que são objetos de ensino em Língua Portuguesa? 


\section{Participantes}

A pesquisa foi realizada em uma escola municipal de Curitiba com uma turma de $3^{\mathrm{o}}$ ano e outra de $4^{\mathrm{o}}$ ano do Ensino Fundamental. Essa escola tem como estudantes crianças da região bem como alguns do município vizinho. É uma região considerada de classe média-baixa, conforme o projeto político pedagógico da escola. O levantamento de dados para este estudo foi realizado de maio a agosto de 2017, totalizando 32 horas. Foram 16 horas de observação, em cada uma das turmas, realizadas pelas pesquisadoras, todas quando as professoras trabalhavam com Língua Portuguesa.

\section{InSTRUMENTO E PROCEDIMENTO DE COLETA DE DADOS}

As observações se deram a partir da pauta de observação construída pelas pesquisadoras e validada por profissionais que atuam na Secretaria Municipal da Educação do Município, bem como por professores mestres e doutores da Universidade Federal do Paraná. A pauta de observação tem como base Viana et al. (2010) e Solé (2012).

Em cada período de observação, o objetivo era verificar quais estratégias eram utilizadas pelos professores, antes, durante e após a leitura dos textos realizados. Vale ressaltar que as estratégias podem ser utilizadas em outros momentos. Também foi realizada a observação acerca dos gêneros textuais utilizados durante os períodos de observação. Para essa pesquisa, a pauta construída conta com 33 itens de observação, divididos em três grupos, antes, durante e após a leitura como segue:

Antes da leitura foi observado se os professores:

- forneciam informações sobre o texto;

- formulavam perguntas para realização de previsões;

- exploravam o título;

- exploravam as ilustrações, quando tinham;

- exploravam o vocabulário;

- falavam sobre o tema;

- perguntavam o que os estudantes sabiam sobre o tema. 
Durante a leitura foi observado se os professores levavam em consideração o momento de realização da atividade e se:

- forneciam cópia dos textos para que os estudantes fizessem as anotações;

- orientavam para que destacassem as palavras desconhecidas durante a leitura;

- orientavam para que destacassem trechos que não compreenderam;

- solicitavam que elaborassem perguntas;

- interrompiam a leitura em momentos estratégicos e solicitavam a opinião dos estudantes;

- interrompiam a leitura e solicitavam que dissessem o que iria acontecer;

- interrompiam a leitura e solicitavam que descobrissem o significado de palavras utilizando materiais como dicionários;

- interrompiam a leitura e solicitavam que descobrissem o significado das palavras por meio de pistas contextuais;

- interrompiam a leitura e solicitavam que descobrissem o significado das palavras analisando a raiz ou seus afixos.

Após a leitura foi observado se os professores:

- falavam sobre as coincidências entre as predições e o que realmente aconteceu;

- exploravam o significado de palavras e expressões que apareciam no texto;

- recomendavam a construção de frases, orais ou escritas, utilizando as palavras destacadas;

- retomavam a(s) palavra(s) destacadas pelos(as) estudantes;

- retomavam o(s) trecho(s) destacados;

- propunham a definição de conceitos, sinônimos e antônimos das palavras ou expressões destacadas;

- formulavam perguntas que exigissem a releitura do texto;

- retomavam as ações/sequência dos fatos presentes no texto;

- propunham perguntas que tratavam da ideia central do texto;

- propunham perguntas sobre as personagens;

- propunham perguntas sobre fatos e opiniões;

- propunham perguntas sobre causas e consequências;

- faziam resumo oral ou escrito;

- faziam esquemas; 
- solicitavam a atribuição de novo título ao texto;

- propunham atividades de continuidade ou finalização de um texto;

- faziam releitura dos textos.

Procedimentos Éticos

O estudo foi submetido previamente ao Comitê de Ética da Universidade Federal do Paraná - Setor de Ciências da Saúde, obtendo parecer de acordo para a sua realização, sob/com o seguinte número de inscrição CAAE: 63495417.6.00oo.0102 sendo inscrito no CEP/SD: 102 - UFPR - Setor de Ciências da Saúde da Universidade Federal do Paraná - SCS/UFPR.

\section{Resultados}

Os textos narrativos - contos, fábulas e mito - foram os mais trabalhados chegando a 50\% dos períodos de observação, ou seja, das 32 horas de observação, 16 horas foram destinadas ao trabalho com textos narrativos. Conforme tabela 1.

\begin{tabular}{c|c|c}
\hline Gênero textual & $\begin{array}{c}\text { Total de } \\
\text { textos trabalhados }\end{array}$ & $\begin{array}{c}\text { Percentual de } \\
\text { tex tos trabalhados }\end{array}$ \\
\hline Conto & 5 & $31,3 \%$ \\
Fábula & 2 & $12,5 \%$ \\
Receita & 4 & $25,0 \%$ \\
Mito & 1 & $6,3 \%$ \\
Sumário & 1 & $6,3 \%$ \\
Reportagem & 1 & $6,3 \%$ \\
Informativo & 2 & $12,5 \%$ \\
\hline Total & 16 & $100,0 \%$ \\
\hline
\end{tabular}

Tabela 1 - Gêneros textuais trabalhados durante o período de observação Fonte: As autoras

E dentre os narrativos, o gênero textual mais trabalhado foi o conto, com 10 horas de trabalho realizado com esse gênero. 
Observando-se cada turma isoladamente, o trabalho com textos narrativos foi muito pequeno na turma de terceiro ano, já no quarto ano, $87,5 \%$ do período de observação o trabalho realizado foi destinado a textos narrativos (contos, fábulas e mitos). No terceiro ano, $50 \%$ do tempo trabalhado foi realizado com o gênero receita. De maneira geral, o conto foi o gênero textual mais trabalhado, em 31,3\% dos momentos de observação.

\begin{tabular}{c|c|c|c|c|c|c|c}
\hline \multirow{2}{*}{ Turma } & \multicolumn{7}{c}{ Gêneros tex tuais } \\
\cline { 2 - 8 } & Conto & Fábula & Receita & Mito & Sumário & Reportagem & Informativo \\
\hline $\begin{array}{c}\text { Terceiro } \\
\text { ano }\end{array}$ & $12,5 \%$ & $0 \%$ & $50 \%$ & $0 \%$ & $12,5 \%$ & $0 \%$ & $25 \%$ \\
$\begin{array}{c}\text { Quarto } \\
\text { ano }\end{array}$ & $50 \%$ & $25 \%$ & $0 \%$ & $12,5 \%$ & $0 \%$ & $12,5 \%$ & $0 \%$ \\
\hline Total & $31,3 \%$ & $12,5 \%$ & $25 \%$ & $6,3 \%$ & $6,3 \%$ & $6,3 \%$ & $12,5 \%$ \\
\hline
\end{tabular}

Tabela 2 - Gêneros textuais trabalhados por turma

Fonte: As autoras

Observou-se um trabalho constante, em ambas as turmas, relativo às características do gênero textual e sua função. As professoras retomavam oralmente características do gênero com os estudantes. Esse trabalho é apontado por Català et al. (2013) como superestrutura, fundamental para a evolução da leitura.

Além da superestrutura é necessário que haja a leitura realizada em sala de aula. Em todos os períodos de observação verificou-se leitora oral pela professora, bem como leitura silenciosa, leitura em voz alta pelos estudantes e a releitura (ver gráfico 1).

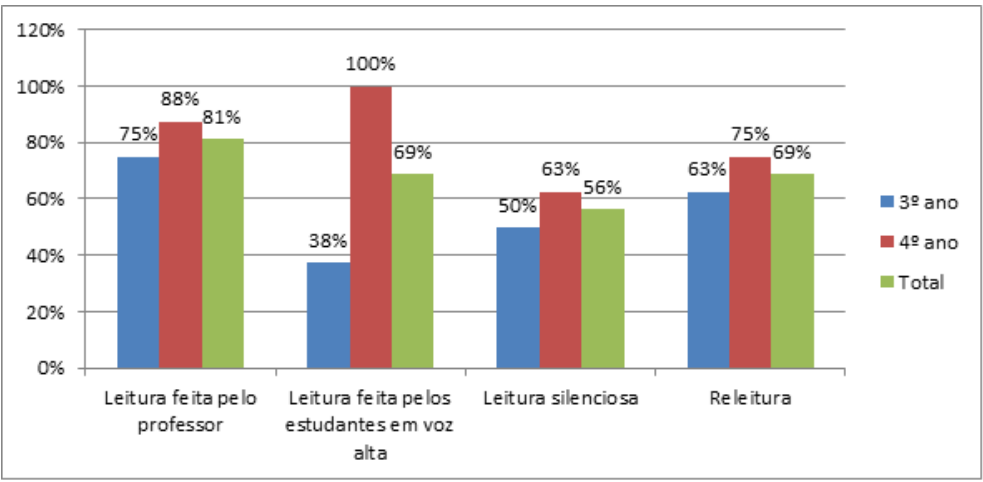

Gráfico 1 - Modalidade de leitura realizada - Fonte: As autoras 
É importante ressaltar que em todos os períodos de observação houve trabalho com a leitura, sendo que $81,2 \%$ dos momentos houve a leitura feita pelo professor. No $4 .^{\circ}$ ano, em todos os momentos da observação houve a leitura em voz alta realizada pelos estudantes. Essa leitura variava entre individual; grupos; turma, etc. Em vários desses momentos as professoras repetiam chamando a atenção para a entonação e solicitando que o estudante lesse novamente, o que se caracteriza como uma adequada estratégia de ensino, tendo em vista que a entonação na leitura está relacionada à compreensão do texto.

Entretanto, observou-se que as explicações que justificassem as pausas e a entonação foram insuficientes no que diz respeito ao o trabalho com os sinais de pontuação. Posteriormente às atividades de leitura, foram realizadas atividades escritas. Vale ressaltar que muitas eram relacionadas à estrutura e à função do gênero textual e poucas as atividades de compreensão (ver gráfico 2).

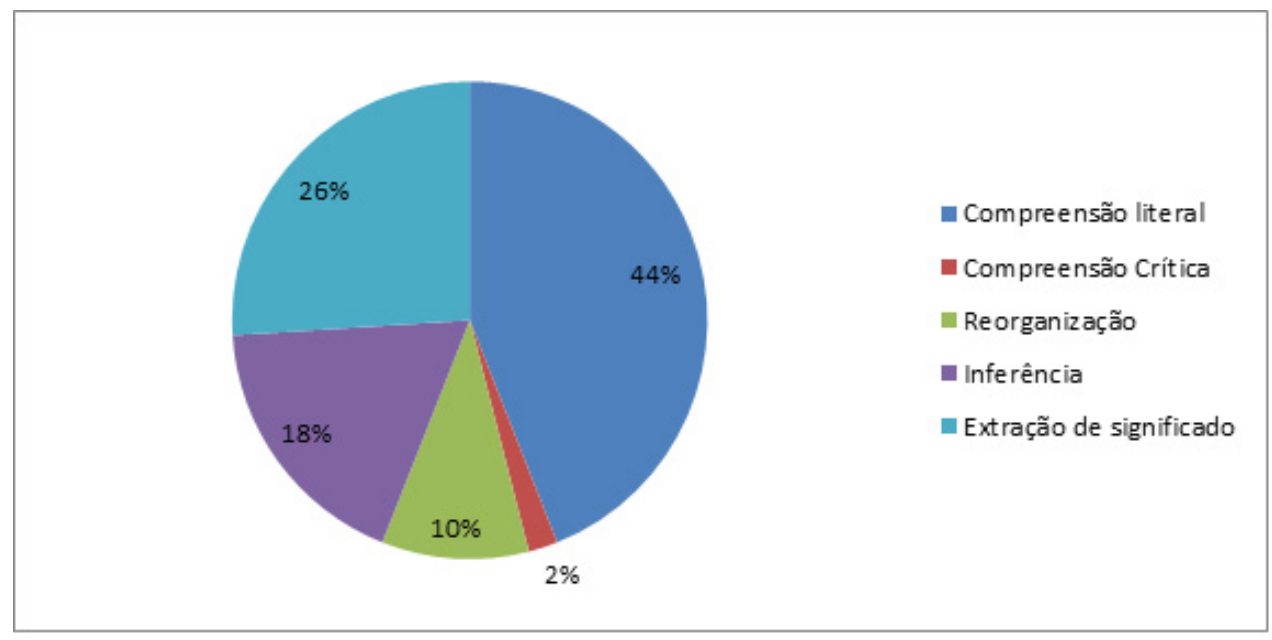

Gráfico 2 - Tipos de atividades de compreensão da leitura

Fonte: As autoras

Durante o período de observação foram realizadas 50 atividades de compreensão da leitura. Como se vê, a compreensão crítica foi a menos trabalhada, e a compreensão literal, foi a mais trabalhada. Esses resultados vem ao encontro do que foi apontado por Catalá et al. (2013), que a compreensão literal é a mais trabalhada nas escolas. 
Ensino da compreensão leitora na prática pedagógica de professores...

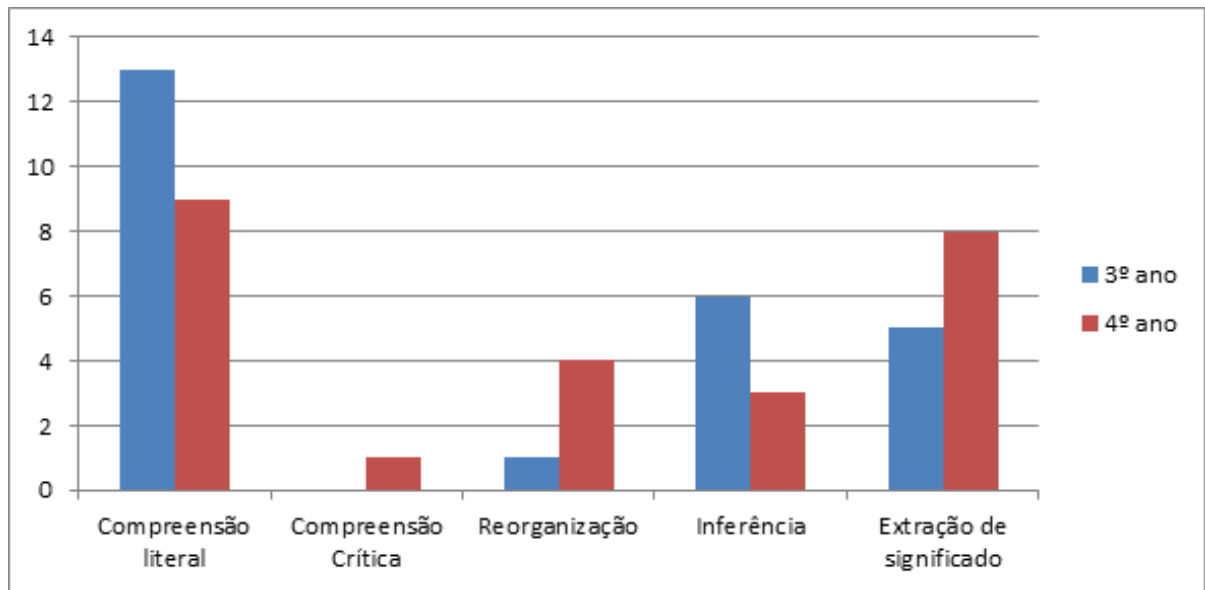

Gráfico 3 - Tipos de atividades de compreensão da leitura por turma Fonte: As autoras

As questões literais, conforme Viana et al. (2010) são necessárias, mas não são suficientes para que os estudantes compreendam integralmente um texto. No terceiro ano o trabalho com os textos não envolveu atividades relacionadas à compreensão crítica em nenhum período. Com relação às questões inferenciais é interessante notar um trabalho maior no terceiro ano, já o trabalho com extração de significado foi maior no $4^{\circ}$ ano.

Durante o período de observação, foram verificadas quantas e quais estratégias as professoras utilizavam. No gráfico 4 está registrada a frequência das estratégias utilizadas pelas professoras antes da leitura.

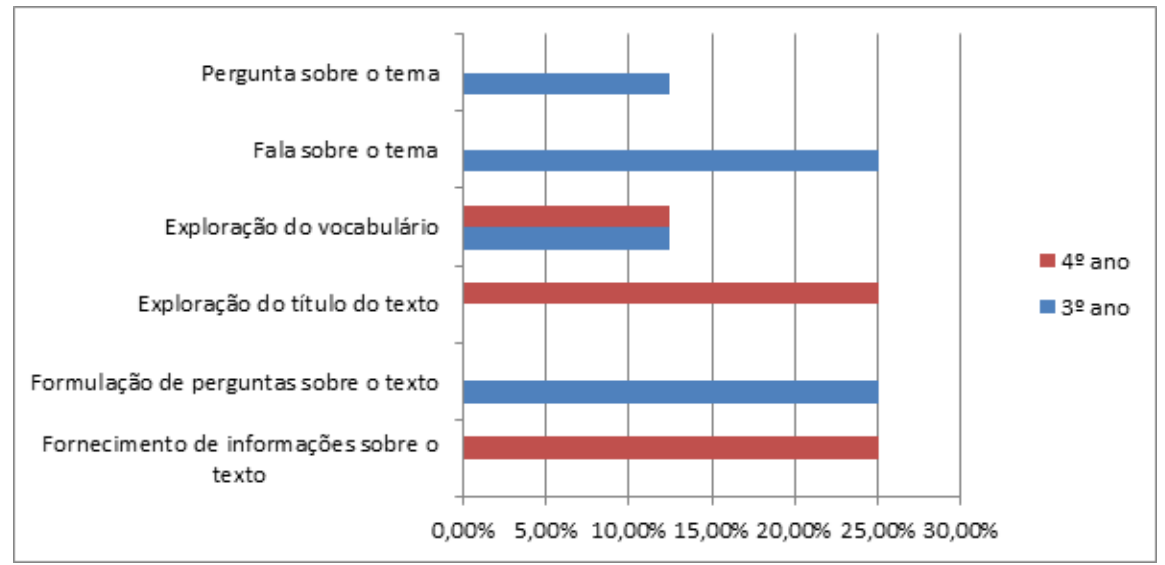

Gráfico 4 - Estratégias utilizadas antes da leitura - Fonte: As autoras 
As estratégias de compreensão da leitura que são indicadas a serem utilizadas antes da leitura foram pouco utilizadas pelas professoras. Vale ressaltar que das seis estratégias, 3 não foram utilizadas em nenhum momento na turma do quarto ano e duas não foram utilizadas em nenhum momento na turma do terceiro ano. Apenas a estratégia Exploração do vocabulário foi utilizada em ambas as turmas.

Uma das estratégias indicadas a ser utilizada antes da leitura é a exploração das ilustrações, quando o texto apresentar. Vale ressaltar que durante o período de observação havia seis textos que possibilitavam o uso dessa estratégia. No terceiro ano, foram 2 textos e a professora utilizou a estratégia em ambos os textos. Já no quarto ano, quatro textos possibilitavam esse trabalho, mas foi realizado em apenas dois deles.

No que se refere às estratégias realizadas durante a leitura, foram analisadas 9 estratégias, entre elas, destacar as palavras desconhecidas pelos alunos.

Também está entre estas estratégias a interrupção da leitura para solicitar que os estudantes digam o que vai acontecer na sequência do texto. É importante salientar que o professor normalmente planeja com antecedência em que momento fará a interrupção, mas a execução da estratégia se dá durante a leitura.

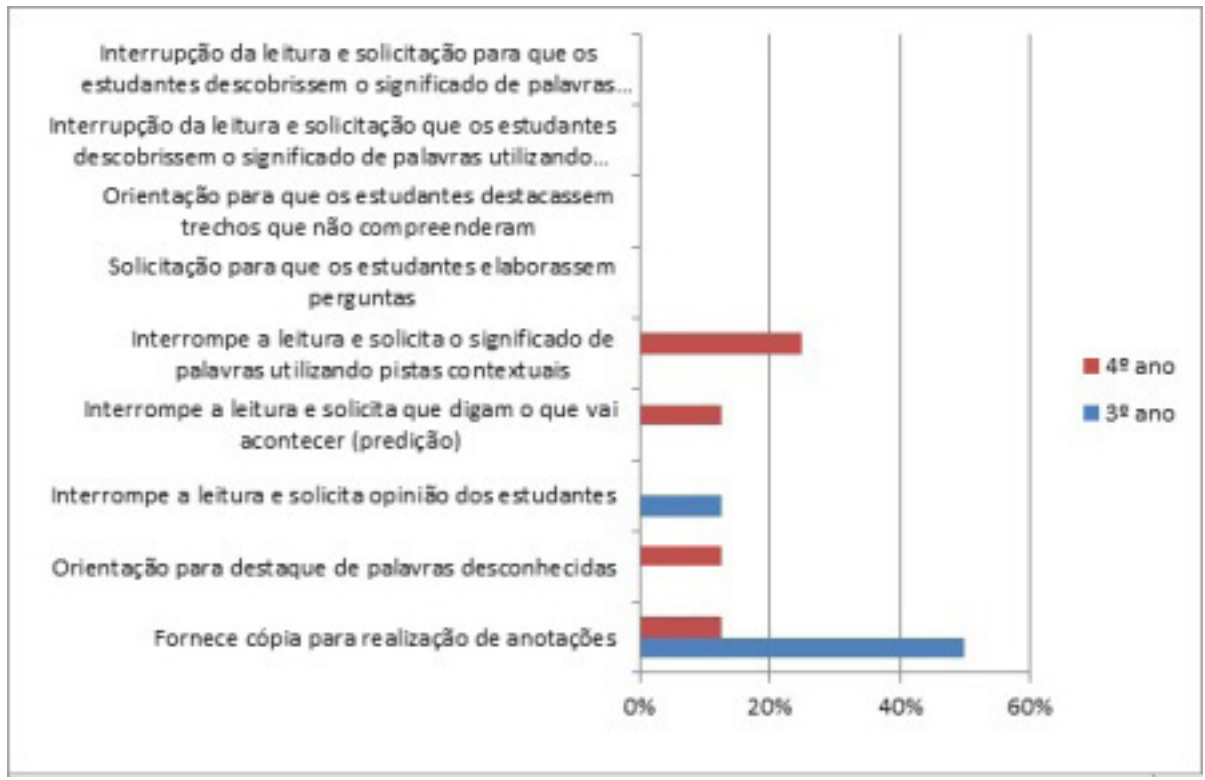

Gráfico 5 - Estratégias utilizadas durante a leitura

Fonte: As autoras 
Foi observada a utilização de poucas estratégias durante a leitura. Das nove estratégias que poderiam ser utilizadas, apenas cinco foram constatadas durante $\mathrm{o}$ período de observação. Sendo que na turma do terceiro ano, apenas duas foram e no quarto ano, apenas quatro estratégias foram utilizadas. A única estratégia utilizada em ambas as turmas, mas com uma frequência muito baixa, foi o fornecimento de cópias para realização de anotações. Dos oito períodos de observação em cada turma, no terceiro ano essa estratégia foi utilizada em quatro períodos de observação, ou seja, 50\%. No quarto ano, em apenas um período de observação, o que corresponde $12,50 \%$, houve o trabalho com essa estratégia.

Quatro das estratégias não foram utilizadas em nenhuma das turmas, são elas: solicitação para que os estudantes elaborassem perguntas; orientação para que os estudantes destacassem trechos que não compreenderam; interrupção da leitura e solicitação que os estudantes descobrissem o significado de palavras utilizando materiais como dicionários e a interrupção da leitura e solicitação para que os estudantes descobrissem o significado de palavras utilizando a análise da raiz e afixos.

O último grupo de estratégias observado refere-se a aquelas que podem ser utilizadas após a leitura. Na pauta de observação elaborada foram elencadas 17 estratégias. A tabela 10 mostra as principais estratégias utilizadas pela as professoras após a leitura dos textos.

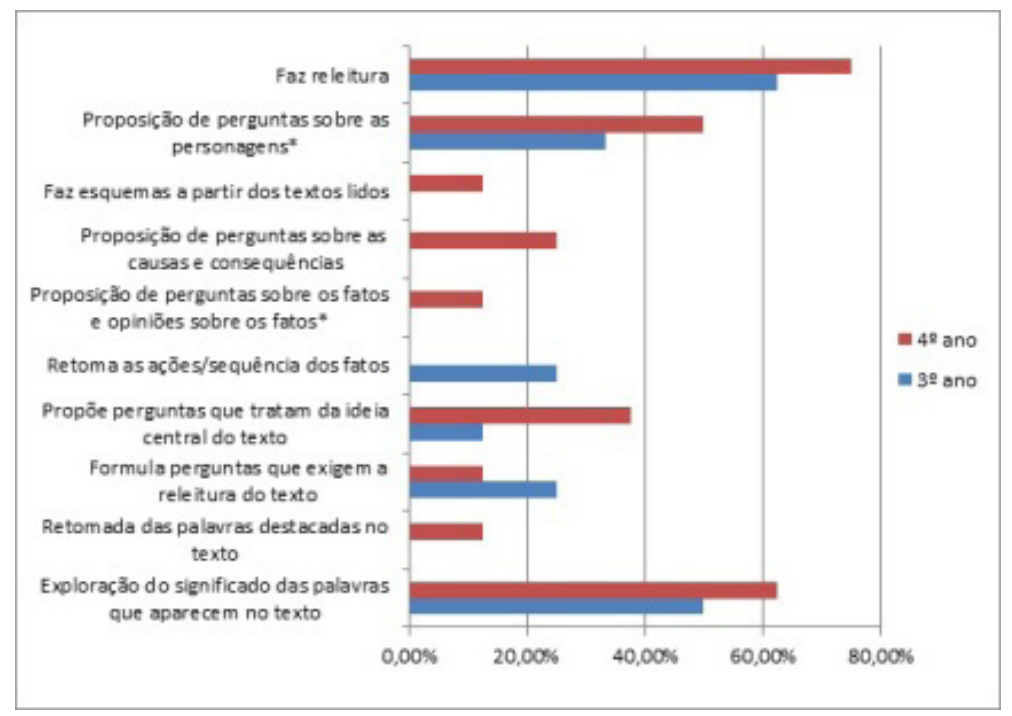

Gráfico 6 - Estratégias após a leitura - Fonte: As autoras

*(Excluídos textos que não possibilitam o trabalho com a estratégia.) 
É interessante observar que apenas três estratégias foram utilizadas em ambas as turmas: formulação de perguntas que exigem a releitura do texto; proposição de perguntas que tratam da ideia central do texto e proposição de perguntas sobre as personagens. As estratégias de exploração do significado de palavras e releitura do texto são as mais trabalhadas em ambas as turmas. Após a leitura do texto, o quarto ano teve mais estratégias utilizadas durante o período de observação.

Das 17 estratégias possíveis após a leitura, 7 não foram trabalhadas em nenhum dos momentos: as coincidências entre a predição e o que acontece no texto; proposição de construção de frases utilizando as palavras destacadas; retomada do trecho destacado; proposição de definição de conceitos, sinônimos e antônimos das palavras destacadas; resumo; atribuição de novo título e continuação ou finalização de um texto. Como se vê nos gráficos 4, 5 e 6 há uma frequência muito baixa de trabalho realizado com estratégias para o ensino da compreensão da leitura.

A estratégia que chama a atenção é a releitura, que no geral, em $68,8 \%$ dos momentos de observação essa estratégia foi utilizada pelos professores das duas turmas. Embora tenha sido realizada com mais frequência, em ambas as turmas, ainda percebe-se que muitas vezes foi realizada mecanicamente, pois os estudantes ainda apresentavam dificuldades na compreensão do que estavam lendo. A releitura é fundamental, pois a repetição da leitura é um procedimento que leva à fluência e, consequentemente, à compreensão.

Uma das formas para que os(as) estudantes compreendam é a realização de inferências, ou seja, o trabalho com as predições. Essa estratégia foi trabalhada apenas uma vez, no quarto ano, mas não foi realizado o confronto entre as predições realizadas e o que realmente aconteceu no texto.

Como visto no gráfico 2, as atividades de compreensão da leitura foram minimamente utilizadas pelas professoras. Isso também acontece com as estratégias antes, durante e após a leitura.

\section{Discussão}

Analisando os resultados dessa pesquisa, foi possível notar que nas turmas observadas as professoras utilizam poucas estratégias e poucas atividades para $o$ ensino da compreensão da leitura, ou seja, não é realizado um trabalho sistemático.

Conforme Viana et al. (2010) o ensino sistemático com atividades de compreensão da leitura aumenta a proficiência leitora. Durante o período da 
Ensino da compreensão leitora na prática pedagógica de professores...

observação os professores utilizaram poucas estratégias de ensino da compreensão da leitura, mas trabalharam outras questões como a função e a estrutura do gênero textual, o que instrumentaliza os estudantes para outros aspectos da língua. A maioria das perguntas realizadas para os estudantes foram para verificação se a resposta está correta ou errada, mas as perguntas voltadas para o ensino, que permitem ao estudante analisar sua resposta, buscar elementos no texto que comprovem essa resposta não foram verificadas em nenhum momento durante a observação. Dessa maneira pode-se dizer que o ensino explícito da compreensão da leitura é pouco realizado em sala de aula.

Há necessidade de trabalho com encaminhamentos pedagógicos para o ensino explícito da compreensão da leitura, pois como apontam Solé (2012) e Viana et al. (2010), o trabalho sistemático com as estratégias de leitura e com as atividades de compreensão é que fazem com que os estudantes avancem na compreensão dos textos que leem.

A partir do que foi discutido nesse trabalho quanto ao ensino sistemático das estratégias de leitura e do que foi observado, aqui são apontadas algumas considerações sobre as implicações pedagógicas para o percurso escolar do estudante. As estratégias de leitura devem ser trabalhadas sistematicamente durante o ensino, pois contribuem para que os estudantes avancem na compreensão do que leem. Durante a leitura é importante que aconteçam as produções de inferências por serem fundamentais para a compreensão dos textos. O professor deve inserir em sua prática questões que façam com que os estudantes apontem possíveis inferências, seja a partir do título do texto, de partes de texto, de ilustrações... Enfim sistematizar o trabalho para ensinar a compreensão de textos utilizando-se de estratégias antes, durante e após a leitura.

\section{REFERÊNCIAS}

ALÉGRIA, J.; LEYBAERT, J.; MOUSTY, P. Aquisição da leitura e distúrbios associados: avaliação, tratamento e teoria. Em J. Grégoire \& B. Piérart (Orgs.). Avaliação dos problemas de leitura: os novos modelos teóricos e suas implicações diagnósticas (p. 105-124) (M. R. B. Osório, Trad.) Porto Alegre: Artes Médicas. (Trabalho original publicado em 1994), 1997.

BRASIL. Indicador de alfabetismo funcional - INAF: Estudo especial sobre alfabetismo e mundo do trabalho. Disponível em: <http://acaoeducativa.org.br/wp-ontent/uploads/2016/o9/ INAFEstudosEspeciais_2016_Letramento_e_Mundo_do_Trabalho.pdf $>$. Acesso em: $27 / 02 / 2018$. 
CATALÀ, G. et al. Evaluación de la comprensión lectora: Pruebas ACL (1. ${ }^{\circ}$ ao $6 .^{\circ}$ de primária). $8 .^{\circ}$ reinpresión. Barcelona, 2013.

COSTA, S. R. Dicionário de Gêneros Textuais. 2. ed. Belo Horizonte: Autêntica Editora, 2009.

GIASSON, J. A compreensão na leitura. Tradução de Maria José Frias. Lisboa, Portugal: Edições ASA, 1993 .

INEP. Instituto Nacional de Estudos e Pesquisas Anísio Teixeira. IDEB Resultados e Metas. Disponível em: <http://ideb.inep.gov.br/>.

JOUVE, V. A leitura. Tradução Brigitte Hervot. São Paulo: Editora UNESP, 2002.

MALUF, M. R. O Psicólogo Escolar e a Alfabetização. In: MARTINEZ, A.M. (Org.). Psicologia Escolar e Compromisso Social. Campinas, SP: Alínea, 2005.

MARCUSCHI, L. A. Produção textual, análise de gêneros e compreensão. 2. ed. São Paulo: Parábola Editorial, 2008.

MORAIS, J. Criar leitores: para professores e educadores. Barueri, SP: Manole, 2013.

OLIVEIRA, M. H. M. A. de. Estratégias de Compreensão de Leitura (resenha). Revista Psicologia Escolar e Educacional, v. 7, n. 1, Campinas, June 2003. Disponível em: <http://www.scielo.br/ scielo.php?script=sci_arttext\&pid=S1413-85572003000100010 >. Acesso em: 27/02/2018.

ROJO, R. Letramento e capacidade de leitura para a cidadania. PUCSP, 2004.

SOLÉ, I. Estratégias de leitura. 6. ed. Porto Alegre: Penso, 1998 (reimpressão 2012).

VIANA, F. L. et al. O ensino da compreensão leitora. Da teoria à prática pedagógica. Um programa de intervenção para o $1^{\circ}$ ciclo do ensino básico. Coimbra: Edições Almedina, 2010.

\section{SOBRE AS AUTORAS:}

Elaine Doroteia Hellwig Braz é graduada em Letras (Universidade Tuiuti do Paraná), tem Mestrado em Educação (Universidade Federal do Paraná). É professora do ensino fundamental na Prefeitura Municipal de Curitiba. Tem experiência na área de Alfabetização e Língua Portuguesa, com pesquisas nos seguintes temas: compreensão da leitura; inferência.

E-mail: elainehellwig@yahoo.com.br.

Sandra Regina Kirchner Guimarães é graduada em Psicologia (Pontifícia Universidade Católica do Paraná), tem Mestrado em Educação (Universidade Federal do Paraná) e Doutorado em Psicologia Escolar e do Desenvolvimento Humano (Universidade de São Paulo). É professora/pesquisadora permanente do Programa de Pós-graduação em Educação da Universidade Federal do Paraná. Tem experiência na área de Alfabetização, Formação de Professores e Psicologia Escolar e Educacional, com pesquisas nos seguintes temas: aprendizagem inicial 
Ensino da compreensão leitora na prática pedagógica de professores...

ำ
의
$\frac{1}{ \pm}$

e aperfeiçoamento da linguagem escrita, habilidades metacognitivas e metalinguísticas, dificuldades de aprendizagem da leitura e da escrita.

E-mail: srkguimaraes@uol.com.br.

Recebido em os de agosto de 2018 e aprovado em 20 de junho de 2019. 